\title{
技術論文
}

\author{
별추적기의 기술개요와 개발동향 \\ 주광혁*, 이상률*
}

\section{Overview of Star Tracker Technology and Its Development Trends}

Gwanghyeok Ju* and Sang-Ryool Lee*

\begin{abstract}
In order to accelerate the evolution of faster, better, cheaper spacecraft, it is evident that greatly enhanced general-purpose attitude determination methods are needed Currently, star tracker sensors based on charge coupled devices (CCD) or active pixel sensors(APS) enable one to obtain the best spacecraft attitude estimation among the existing sensors for attitude determination. In this paper, basic principles of star tracker technology are explained including major issues arising in design and development of star tracker. Also, an historical overview and worldwide survey associated with various star trackers from star scanner through microelectromechanical system(MEMS)-based star tracker is offered.
\end{abstract}

\section{초 록}

전세계적으로 적용되는 개발개념인 보다 빨리, 더 좋게, 더 값싼 위성을 설계하는 일에 있어 향상된 자세결정시스템을 도입하는 것은 자명한 일이라고 할 수 있다. 오늘날 $\mathrm{CCD}$ 나 APS 기반의 별추적기는 현존하는 위성의 자세결정용 센서중에서 가장 좋은 정밀도를 제공하고 있다. 본 논문에서는, 별추적기의 기본적인 동작원리와 관련 기술의 개요를 소 개함과 동시에 별추적기 개발에서 주요 이슈가 되었던 기술들을 비교 분석한다. 또한 별 스캐너로부터 MEMS기술을 적용한 별추적기에 이르기까지, 별추적기의 간추린 역사와 세 계 각국에서의 개발현황을 소개한다.

Key Words : Spacecraft(인공위성), Star Tracker(별추적기), Star Sensor(별추적기), Attitude Determination(자세결정)

\section{I. 서 론}

인공위성의 자세정보를 제공하는 다양한 센서 중에서 가장 뛰어난 정확도를 제공하여주는 것이 Star Tracker(별추적기 또는 별센서, 이하 별추적 기)로 알려져 있다. 일정한 물리적 원리에 따라 단순하게 반응하여 측정하고자 하는 위치나 자세 에 해당하는 아날로그/디지털 신호를 출력하는

†2010년 1월 25일 접수 2010년 2월 25일 심사완료

* 정회원, 한국항공우주연구원 위성연구본부

교신저자, E-mail : ghju@kari.re.kr

대전광역시 유성구 과학로 115 번지
기존 자세 결정센서와는 달리, 별추적기는 하늘 의 별 사진을 찍어 후처리에 필요한 화상처리를 하는 $\mathrm{CCD}$ 카메라와 별 카탈로그를 저장하고, 저 장된 별의 패턴과 관측된 별의 패턴을 비교 분석 하여 인공위성의 자세를 결정하고, 결정된 자세 를 인공위성의 자세제어 시스템에 전달하여 주는 탑재(On-Board)컴퓨터 및 관련 소프트웨어로 구 성되어 있는 하나의 통합시스템이다.

본 논문에서는, 별추적기의 기본적인 동작원리 와 관련 기술의 개요를 소개함과 동시에 별추적 기 개발에서 주요 이슈가 되었던 기술들을 비교 분석한다. 또한 Star Scanner로부터 MEMS기술을 적용한 별추적기에 이르기까지, 별추적기의 간추 
린 역사와 미국과 유럽을 중심으로 한 세계 각국 에서의 개발현황을 소개한다.

\section{ㅍ. 별추적기 기술의 개요}

\section{1 별추적기의 자세결정원리}

일반적으로 인공위성을 포함한 우주비행체의 자세는 비행체의 세 축에 대한 Euler회전각도인 피치(Pitch), 롤(Roll), 요(Yaw)로 정의 되는 것이 일반적이다. 이 자세각들은 비행체의 몸체에 고 정된 좌표계가 관성좌표계의 기준 위치로부터 얼 마만큼 회전되었나를 나타낸다. 정밀한 자세결정 을 위해서는 정확하게 알려져 있으면서도 궤도상 에서 쉽게 관측할 수 있는 외부의 기준점이 있어 야 하는데 현재 가장 정확한 자세기준을 제공해 주는 것으로 알려져 있는 천체는 별이다. 별추적 기는 카메라를 이용하여 천구의 별들을 관측하고 영상 소자에 포착된 별들을 인식하여 우주비행체 의 자세를 측정하는 장치이다. 온보드상에 탑재 된 별 카탈로그상의 별의 패턴과 관측된 별의 패 턴이 일치하면 별추적기의 시선벡터가 지향하는 방향을 별 카탈로그에서 얻을 수 있으므로 이렇 게 얻어진 방향벡터와 우주비행체의 기준좌표계 에 대한 변환만 고려하면 우주비행체의 자세를 측정할 수 있다. 자세한 자세결정원리 및 동특성 에 대한 사항은 참고문헌 (3)과 (8)에 잘 정리되 어 있으므로 생략한다.

\section{2 별추적기의 구조}

현재 가장 보편화되어 있는 $\mathrm{CCD}$ 소자를 사용 한 고정헤드형(Fixed-Head) 별추적기 (2.3절 참 조)를 기준으로 한 별추적기의 구조는 크게 태 양, 지구, 달 등의 광원으로부터 오는 빛을 차단 해 주는 시야각제한기(Lightshade 또는 Baffle) 와 렌즈 및 광학계소자 $(\mathrm{CCD})$, 열제어소자(Peltier Cooler) 로 구성된 광학계, 전력공급장치와 $\mathrm{CCD}$ 드라이브 (Focal Plane Electronics) 및 $\mathrm{CCD}$ 소자 의 냉각을 위한 Cooler를 포함하는 전자계, 별추 적기의 영상 정보를 변환하는 $\mathrm{A} / \mathrm{D}$ 변환기와 이 렇게 읽혀진 정보를 컴퓨터에 전달하는 데이터 전송 장치(1553B 데이터 버스, RS422 접속보드) 로 구성된 데이터 처리계, 마이크로프로세서부에 탑재되는 별인식, 별추적 및 자세결정 알고리즘 과 별자리의 위치 및 등급 정보를 저장하는 별 카탈로그 등으로 구성된 $\mathrm{S} / \mathrm{W}$ 구성부와 새시를 포함한 구조물로 이루어진 기계구성부로 이루어 져 있다. ${ }^{(1,2)}$

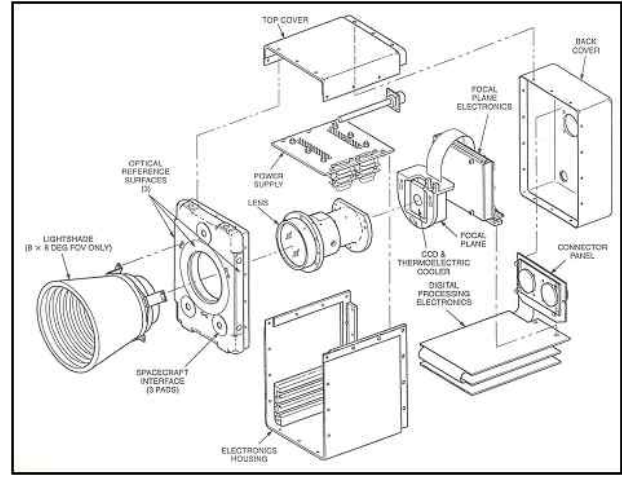

그림 1. 별추적기의 일반적인 구조

\section{3 별추적기의 분류}

별추적기는 별을 추적하는 원리에 따라 별스 케너(Star Scanner), 김벌형 별추적기(Gimbaled Star Tracker), 고정헤드형 별추적기(Fixed-Head Star Tracker)의 세가지로 분류하는 것이 일반적 이나 ${ }^{(3)}$, 별을 감지하는 시야각(이하 $\mathrm{FOV}$, Field-of-View)의 크기에 따라 넓은시야각(Wide $\mathrm{FOV}$ ) 별추적기와 좁은시야각(Narrow FOV) 별 추적기로 나눌 수 있으며 별의 영상을 감지하는 초점면(Focal Plane)의 영상소자의 종류에 따라 IDT(Image Dissector Tube)형 별추적기, CID형 (Charge Injection Device)형 별추적기, $\mathrm{CCD}$ (Charge Coupled Device)형 별추적기, APS(Active Pixel Sensor)형 별추적기 등으로 분 류하기도 한다.

\subsection{1 별추적 메커니즘에 따른 분류}

\section{(1) Star Scanner}

별의 탐색 및 감지를 하기 위해 위성의 회전 을 이용한다. 위성의 회전에 따라 스캐너의 시야 범위 내의 많은 슬릿을 통해 별들이 지나가게 된 다. 슬릿을 통해 몇 개의 별이 교차된 후에 위성 의 자세를 추정하게 된다. 자세측정을 위해 사용 할 수 있는 별은 2 등성 이상의 밝은 별들이므로 다른 별추적기에 비해 상대적인 정밀도가 떨어진 다. 최근 대표적인 모델로는 Ball Aerospace사의 CT-632가 있으며 회전안정화방식의 위성에 주로 탑재되는 것이 일반적이다.

(2) 김벌형(Gimbaled) 별추적기

이름 그대로 별추적기를 Gimbal 위에 고정시 키고 Gimbal의 기계적 움직임을 통해 별을 감지 추적한다. 이러한 방식의 별추적기는 위성이 다 양한 자세로 운용될 때 흔히 사용하게 된다. Gimbal에 장착된 별추적기는 매우 작은 광학적 
$\mathrm{FOV}$ (보통 $1^{\circ}$ 이하)를 갖는다. 그러나, Gimbal Mounting 구조가 넓은 유효 FOV을 제공하게 된 다. 이러한 형태의 별추적기는 상대적으로 적은 수의 목적 별을 사용하여 운용된다.

(3) 고정머리형(Fixed-Head) 별추적기

세 가지 형태의 별추적기 중 $\mathrm{CCD}$ 카메라의 발달과 함께 가장 많이 사용되어지는 형태이다. 제한된 $\mathrm{FOV}$ 에 대해 전자적인 탐색과 추적 능력 을 갖고 있다. 매우 넓은 시야범위를 가지며, 미 리 입력된 밝기를 갖는 별을 찾아 위성체를 지향 시킬 때까지 전자적으로 스캔한다. 위성체의 자 세 정보는 시야범위 내의 별의 움직임으로 나타 나게 된다. 자세정보를 얻는 방법은 앞에서 설명 되었으며 위성의 자세정보를 얻기 위해서 우선적 으로 별추적기는 포착(Acquisition) 모드에 들어 간다. 포착 모드에서는 $\mathrm{FOV}$ 내에 들어온 별들 중에 적절한 밝기의 별을 선정하는 것이다. 포착 모드에서 충분한 밝기의 별을 찾아내게 되면 추 적 모드에 들어가게 되는데, 우선적으로 별추적 기 내의 데이터베이스에 저장되어 있는 정보와 $\mathrm{CCD}$ 영상에 포착된 별의 정보를 비교하여 별을 인식하게 된다. 별이 인식되게 되면 데이터베이 스 내의 별의 위치 정보를 사용하여 위성의 자세 정보를 얻어낸다. 별이 $\mathrm{FOV}$ 에서 사라질 때까지 추적 모드를 통해 계속적으로 별을 추적하게 된 다. 추적하던 별이 $\mathrm{FOV}$ 에서 벗어나면 다시 포착 모드로 전환하여 적당한 밝기의 별을 다시 포착 하게 된다. 별추적기에서는 이러한 과정을 반복 하여 위성의 자세 정보를 얻게 된다.

\subsection{2 별감지 $\mathrm{FOV}$ 의 크기에 따른 분류}

\section{(1) Narrow FOV 별추적기}

초기에 개발된 별추적기의 경우 화상 소자의 화소수가 상대적으로 적고 민감도(Sensitivity)가 낮아 별을 감지하는 $\mathrm{FOV}$ 가 그리 크지 않았다. 넓은 $\mathrm{FOV}$ 를 확보하기 위하여 Gimbal을 사용하 기도 하였으며 별의 민감도를 높여 제한된 $\mathrm{FOV}$ 에 들어오는 별의 수를 증가시킴으로써 자세결정 도를 확보하기도 한다. 특별히 정해진 범위는 없 으나 대채로 $\mathrm{FOV}$ 가 10 도 이하를 가진 별추적기 로 분류하는 것이 일반적이다.

(2) Wide FOV 별추적기

상대적으로 넓은 $\mathrm{FOV}$ 를 가진 별추적기를 일 컫는 말로 주어진 FOV내에 들어오는 별의 수가 일반적으로 많아 감지되는 별의 민감도를 높이지 않아도 되어 별 카탈로그의 정보의 크기가 크지 않아도 되는 장점이 있으며 화면이 넓어 한번 인 식된 별의 추적이 용이하며 이를 이용하여 회전
각속도를 측정할 수 있는 Gyroless효과를 기대할 수 있으나 별의 수가 많아질 경우 별 패턴을 인 식하는 알고리즘이 복잡해 지고 자세결정이 느려 지는 경우가 생길 수 있는 단점이 있다.

\subsection{3 화상소자에 따른 분류}

(1) IDT(Image Dissector Tube)형 별추적기

1960년대와 1970년대에 별추적기의 영상소자 로 널리 사용되었던 Image Dissector는 Photocathode와 Sampling Aperture사이에 Electron Imaging Section 과 Electron Deflection Section을 가진 Photomultiplier Tube이다.

별 영상이 광학계에 의해 $\mathrm{IDT}$ 의 Photocathode 에 집중이 되면 광학영상은 광전자의 방출에 의 해 전자영상으로 변환되고 광전자는 Magnetic Deflecting Coil에 의해 고정된 수광부의 Aperture를 따라 굴곡이 일어난다. 이 Aperture 는 Photocathode상에 작은 IFOV (Instantaneous $\mathrm{FOV}$ )를 형성하게 되는데 IFOV가 Deflection Coil에 의해 변환되는 전류에 따라 고정된 영상 을 일정한 방식으로 스캔하게 되고 일정 Threshold이상의 영상신호를 찾게 되면 전자처리 부에서 추적패턴을 인식하는 구조로 되어 있다. $\mathrm{CCD}$ 를 이용한 별추적기가 등장하기 전에 가장 널리 사용되었던 방식이나 온도변화와 자장계의 변화에 민감하여 구조적인 Drift 오차를 발생시 키며, Image Dissector가 FOV이내의 적은 영역 으로 오는 신호전류만 측정할 수 있기 때문에 많 은 수의 별을 동시에 감지하기가 어려우며, 고전 압이 필수적으로 적용되는 관계로 장기간의 임무 에는 적합하지 않은 단점이 있다. 미국의 초기 우주왕복선 모델에도 사용된 바 있다.

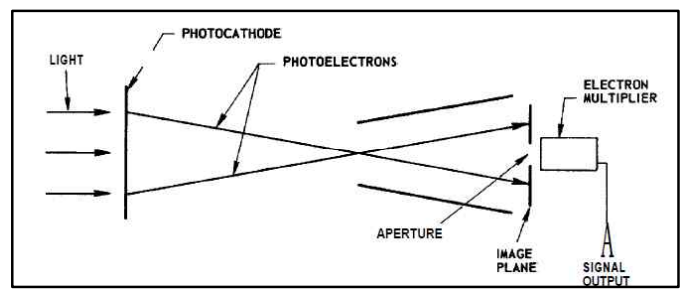

그림 2. IDT의 작동원리

(2) CID(Charge Injection Device)형 별추적기

$\mathrm{CID}$ 는 $\mathrm{CCD}$ 와 더불어 $\mathrm{MOS}$ 기술을 기반으로 광자에 의해 발생된 전하를 보관, 전송한다는 점 에서 같은 전하전달장치(Charge Transfer Device, CTD) 라고 할 수 있다. 그러나 Column 에 따라 픽셀에서 픽셀로 전하를 전달하는 구조를 가진 $\mathrm{CCD}$ 와는 달리 $\mathrm{CID}$ 는 픽셀간에 전하를 직접 
전달하지 못하고 픽셀내에 있는 충전영역으로 전 하를 교환한 다음 Readout 주기가 끝나면 픽셀에 인접한 Substrate로 전하가 방출되는 방식을 취한 다. 픽셀간의 임의 접근성과 높은 Fill-Factor에도 불구하고 높은 버스 정전용량과 불완전한 전하전 달구조로 인하여 많은 모델이 활발하게 개발되지 못하고 $\mathrm{CCD}$ 방식에 의해 사장되고 말았다.

(3) $\mathrm{CCD}$ (Charge Coupled Device)형 별추적기

$\mathrm{CCD}$ 는 Charge Coupled Devices의 약어로 반 도체소자의 일종인 전하결합소자를 말하며 하나 의 소자로부터 인접한 다른 소자로 전하를 전송 할 수 있는 소자를 말한다. $\mathrm{CCD}$ 별추적기의 경우 렌즈로 들어온 빛은 각각 픽셀(pixel)이라 불리우 는 수광면에 결상되는데 각 픽셀이 그 빛에 대한 전하를 저장하고 이 전하의 크기로 명암 정도를 판단한 후 변환장치로 보내 전기신호로 변환시켜 출력하는 방식으로 별을 감지한다. 아날로그 신 호로 출력된 별의 영상은 $\mathrm{A} / \mathrm{D}$ 변환기에 의해 디 지털로 변환되어 마이크로프로세서에 의해 전달 되어 자세정보 측정을 위한 후속처리가 이루어지 게 된다. $\mathrm{CCD}$ 방식은 영상 신호처리 영역이 작 은 $\mathrm{CMOS}$ 방식에 비해 미세한 표현과 섬세한 색 상구분이 가능하므로 오늘날 가장 널리 사용되는 형태의 별추적기이다.

(4) APS (Active Pixel Sensor)형 별추적기

$\mathrm{APS}$ 라 불리우는 $\mathrm{CMOS}$ 영상소자는 소비전력 과, 크기 그리고 가격에서의 이점때문에 $\mathrm{CCD}$ 를 필요로 하는 많은 영상기기에 급속도로 확산되는 추세에 있다. 초기 $\mathrm{CMOS}$ 는 공정기술의 부족으 로 인하여 FPN(Fixed Pattern Noise)을 비롯한 Noise로 인한 Image Quality가 CCD에 비해 열 등하고, $\mathrm{CCD}$ 대비 회로가 복잡하며 Package Density가 낮고 Cost측면에서 $\mathrm{CCD}$ 에 비해 차이 가 없는 관계로 개발이 포기되었다가 $\mathrm{CMOS}$ 공 정기술이 획기적으로 개선되기 시작된 1990년대 Amplified MOS Imager 발표를 시작으로 1993년 Edinburgh 대학에서 CMOS Type Camera Chip 을 발표하였으며, JPL에서 CMOS Type Active Pixel Sensor(APS)를 발표하여 본격적인 CMOS Image Sensor의 개발이 시작되었다.

$\mathrm{CCD}$ 와는 달리 $\mathrm{CMOS}$ 영상센서는 수광센서배 열부와 같은 Die에 아날로그 신호와 디지털 신 호의 프로세싱회로를 집적하여 표준적인 $\mathrm{CMOS}$ 반도체 공정으로 만들어진다. $\mathrm{APS}$ 의 구조는 빛 을 받아 들이는 수광부의 경우 $\mathrm{CCD}$ 와 같이 픽 셀(Photo Diode 또는 Photo Transistor)로 이루 어져 있으나 각각의 픽셀내에 포토디텍터와 영상 해독용 증폭기(Amplifier)가 결합되어 내장되어
표 1. CCD vs. APS 센서의 특성 비교

\begin{tabular}{c|c|c}
\hline & CCD & APS \\
\hline 센서/주변장치 & 분리 & 통합가능 \\
응답성 & 낮음 & 높음 \\
감도/선명도 & 높음 & 낮음 \\
잡음 & 낮음 & 높음 \\
픽셀 균일성 & 양호 & 상대적 열세 \\
암전류특성 & 양호 & 상대적 열세 \\
영상처리속도 & 느림 & 빠름 \\
Antiblooming & 양호 & 일부 양호 \\
가격 & 상대적 고가 & 상대적 저가 \\
생산 & & 대량생산 가능 \\
소비전력 & 높음 & 낮음 \\
우주환경 내구성 & 보통 & 좋음 \\
\hline
\end{tabular}
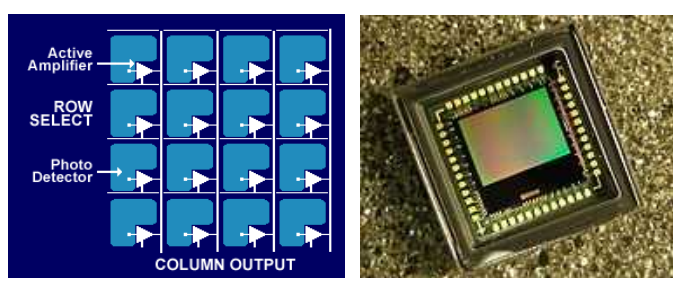

그림 3. APS의 내부구조

있어서 픽셀에서 픽셀로 전하가 전달되는 $\mathrm{CCD}$ 방식과는 달리 단일 픽셀의 영상 신호가 $\mathrm{X}-\mathrm{Y}$ 금 속와이어를 통해 바로 전달되는 구조를 갖고 있 다. $\mathrm{A} / \mathrm{D}$ 변환기가 소자에 포함되어 있어 중심찾 기(Centroiding) 알고리즘을 구현한 로직을 소자 에 포함시킬 수 있을 뿐 아니라 탑재 컴퓨터 하 드웨어에도 바로 연결할 수 있으며, $\mathrm{CCD}$ 에 비해 전력소모도 훨씬 적은 장점이 있어 소형 저전력 이 요구되는 초소형 위성에도 적합하다.

초기에는 Fill Factor와 Quantum Efficiency가 낮고 검출 노이즈가 높아 $\mathrm{CCD}$ 에 비해 영상품질 이 많이 떨어졌으나 3중 트랜지스터와 박막을 채 택한 방식을 통해 기존의 단점을 보완하고 방사 선에 내구성이 강하도록 설계한 $\mathrm{CMOS}$ 기반의 우주용 영상센서가 이미 실용화되어 그 사용범위 가 급속도로 확대되는 실정이다. 우주용 $\mathrm{CMOS}$ 센서를 공급하는 업체는 Fill Factory, IMEC 및 Rockwell Scientific 등이 있으며 Jena Optronik 의 ASTRO APS 등이 상용화되어 있다.

\section{III. 국내외 개발동향}

\section{1 국외개발동향}

\section{1 .1 초기 별추적기}

항법정보를 얻기 위해 별을 이용한 것은 고대 로 거슬러 올라 가는데 북극성을 이용하여 방향 
을 설정하여 여행의 이정표로 삼아 왔던 것이 누 구나 다 아는 좋은 예이다. 이후 중세시대에 이 르러서는 삼각측량, 별 카탈로그 및 지역시간정 보 등을 이용한 Sextant가 개발되어 지구상의 어 느 곳에서도 위도와 경도를 측정할 수 있는 기구 로 자리매김을 해왔다. 별추적기가 항공우주비행 체에 본격적으로 사용된 것은 1940년대 후반부터 라고 할 수 있다. 초기에 사용되었던 별추적기는 광전자증배판(photomultiplier) 와 기계식Gimbal 을 조합한 형태가 주를 이루었으나 짧은 시간의 임무를 수행하는 비행기, 미사일, 풍선기구 (balloon), 인공위성에 주로 탑재되었다. $\mathrm{CCD}$ 가 개발되기 전 1950-60년대에는 광전자증배판에 전 자식의 Gimbaling과 Modulation을 결합한 IDT 를 채용한 별추적기가 주류를 이루어 아폴로, 마 리너, 바이킹 등의 주요 행성탐사위성에 사용되 어 왔다.

\subsubsection{CCD형 별추적기 ${ }^{(4,5,6,7,8)}$}

오늘날 가장 보편화되어 있는 $\mathrm{CCD}$ 타입의 별 추적기의 시초는 1976년에 미국NASA JPL(Jet Propulsion Laboratory) 연구진에 의해 개발된 STELLAR이다. ${ }^{(4)}$ STELLAR는 Fairchild사의 100 x $100 \mathrm{CCD}$ 센서와 INTEL사의 8080 마이크로프 로세서를 채택하고 10 개의 별을 동시에 추적할 수 있으며 약 $7 \mathrm{arcsec}$ 의 정밀도에 3 도의 $\mathrm{FOV}$ 를 갖는 것이었으며 소프트웨어의 변경을 통해 광범 위한 우주비행임무를 수행하도록 설계되어 그 당 시의 별추적기에서는 볼 수 없었던 획기적인 구 조로 설계되었다. 이후 NASA JPL에서는 관측용 기구와 행성탐사위성 등 다양한 비행체에 STELLAR시리즈를 개발하여 탑재한 바 있으며 STELLAR 시리즈는 당시 다른 형태의 별추적기 를 제작해오던 Ball Aerospace와 HDOS(Hughes Danbury Optical Systems)에 영향을 미쳐 CCD 를 채택한 별추적기의 시대를 여는 견인차 역할 을 하였다. 1980년대에 들어 NASA JPL에서는 ASTROS라는 CCD별추적기 시리즈를 개발하여 우주왕복선에 탑재한 자외선 망원경실험과 마리 너 2호 및 $\mathrm{CRAF}$ 위성에 탑재하여 성공을 거둔 바 있다. $\mathrm{ASTROS}$ 별추적기는 $\mathrm{RCA} \mathrm{CCD}$ 와 Texas Instrument의 SBP 9889 마이크로프로세서 를 기반으로 하여 $8.2 \mathrm{Mv}$ 까지 감지할 수 있고 3 개의 별을 동시에 추적할 수 있는 기능을 가지고 있었으나 전력소모가 상대적으로 크고 중량이 $28 \mathrm{~kg}$ 나 나가는 대형 시스템이었다.

CCD가 개발된 1970 년대 초부터 NASA JPL의 주도로 신개념의 별추적기 연구가 계속적으로 진
행되어 온 반면 산업체에서 세계 별추적기 시장 을 주도해 온 곳은 단연 미국의 Ball Aerospace 사라고 할 수 있다. ${ }^{(9)}$ 1967년 창업한 이래 7세대 의 별추적기와 2 세대의 Star Scanner를 개발, 생 산해 오고 있으며 20여 종류의 별추적기를 약 400여대 정도 판매한 실적을 기록하고 있다. 1980년대에 이르기 까지 IDT를 이용한 별추적기 를 주력으로 생산해오던 Ball Aerospace는 CCD 를 채택한 CT-600시리즈를 선 보였다. CT-600시 리즈는 다양한 $\mathrm{FOV}$ 와 민감도 및 중량을 가진 디자인과 간단한 소프트웨어 변경을 통한 다양한 임무요구조건을 만족하는 것으로 알려져 있으며 대체적으로 수 $\operatorname{arcsec}$ 의 자세정보를 제공한다. CT-600시리즈 가운데 1988년에 소개된 CT-601은 $\mathrm{CCD}$ 를 채택한 6세대 최초의 모델로서 $3 \mathrm{arcsec}$ 의 자세정밀도와 7.8 도 $\times 7.8$ 도 $\mathrm{FOV}$ 및 중량 7.7 $\mathrm{kg}$ 를 가진 다소 무거운 별추적기였다. 같은 성능 에 중량과 소요전력만 다소 줄인 모델이 CT-602 이며 FOV를 20도 x 20도로 확대하면서 롤(roll) 방향의 정밀도를 향상시킨 모델이 CT-621이며 CT601과 CT621의 성능을 결합하여 중량, 부피, 소모전력을 최소화 한 모델이 CT-631이다. CT-631은 Wide FOV (18도 x 18도)에 중량 5.5 파운드인 소형 경량 별추적기로서 정밀도는 다소 떨어지나 Gyro가 필요없는 소형 위성에 적합하 도록 설계된 모델이다. CT-633은 CT-600시리즈 가운데 가장 최신 모델로 CT-631의 사양과 성능 을 기반으로 설계되었으며 기존의 별추적기가 별 의 중심위치만 출력하여 주던 방식에서 탈피하여 우주비행체의 자세를 쿼터니언(Quaternion)형태 로 출력하여 줄 뿐 아니라 비행체의 갑작스런 회 전 등으로 인하여 자세정보를 잃어 버렸을 때에 도 ('lost-in-space' mode) 자세를 쉽게 찾을 수 있는 자율적이고도 지능화된 시스템이다. 이밖에 도 회전안정화(Spin-Stabilized)방식의 위성을 위 한 Star Scanner인 CT-632와 우주왕복선 전용인 CT-611이 있다. 2000년대에 들어서면서 Ball Aerospace는 신개념의 별추적기인 Aspect Camera Assembly(이하 ACA)와 Visible Imaging Camera(이하 VIC)를 발표하였다. ACA는 망원경 과 카메라를 겸한 모델로 2개의 1024 x 1024 $\mathrm{CCD}$ 를 기반으로 하여 2 개의 독립된 별 영상을 처리할 수 있도록 되어 있으며 자세결정정밀도가 $0.1 \mathrm{arcsec}$ 까지 구현되는 현존 최고의 별추적기 모델이라 할 수 있다. 반면 VIC는 CT-63x모델을 기반으로 한 별추적기이나 영상처리를 위한 소프 트웨어를 추가하므로써 지구 지표면이나 구름 등 의 영상을 제공하는 원격 지구센서로도 사용되는 신개념의 별추적기이다. 
Ball Aerospace와 더불어 1990년대 중반까지 세계 별추적기 시장을 양분했다고 해도 과언이 아닐만한 회사가 $\operatorname{HDOS}^{(10)}$ (이후 Raytheon Optical Systems, BF Goodrich로 변경)이다. Perkin-Elmers Electro-Optics Technology Division으로 출발한 HDOS사는 1970년 후반에 $\mathrm{CCD}$ 센서를 이용한 Solid State Starmapper의 개 발을 시작으로 1980년대에 CCD센서를 탑재한 ASTRA시리즈(HD-100x)와 1990년대에 소형 경량 의 HD-1003시리즈를 개발하였다. 특히 HD-1003 은 INTEL 8086프로세서를 탑재하고 중량이 $3 \mathrm{~kg}$ 이내인 소형 별추적기이며 25도까지 $\mathrm{FOV}$ 를 자 유자재로 확장가능하며 다른 별추적기에 비해 Update Rate $(10 \mathrm{~Hz})$ 이 상대적으로 빠르고 다양 한 통신 인터페이스를 제공하는 관계로 90년대 들어와 주목을 받아왔다. HDOS는 Ball Aerospace 에 비해 개발된 모델의 종류는 적으나 Ball Aerospace에 비해 일찍 $\mathrm{CCD}$ 센서를 채택한 별추적 기 개발에 주력하여 보다 가볍고 진보된 제품으로 $\mathrm{CCD}$ 별추적기 시장의 많은 부분을 담당하여 왔다.
그러나 1990년대 중반까지 CT-633을 제외하고 는 대부분의 별추적기가 lost-in-space의 기능이 없을 뿐 아니라 자세정보대신에 별의 중심위치만 출력하여 주는 기능만 제공하여 주는 관계로, 별 추적기를 우주비행체에 탑재하고자 하는 사용자 가 별 패턴인식 알고리즘과 자세결정 알고리즘을 구현하는 작업을 감당하여야만 했다.
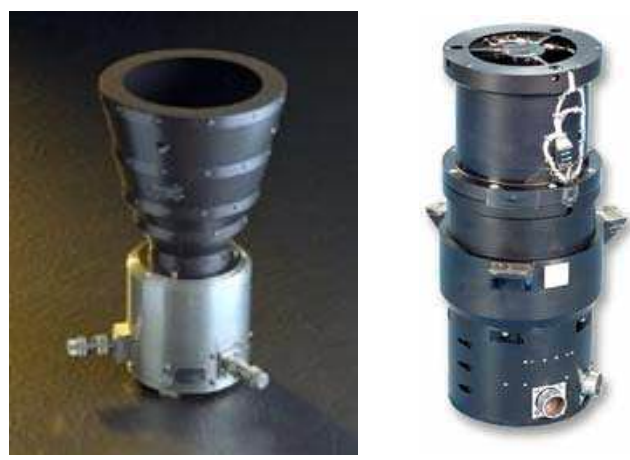

그림 4. Ball Aerospace의 CT-633과 ACA

표 2. $\mathrm{CCD}$ 형 별추적기의 특성 비교

\begin{tabular}{|c|c|c|c|c|c|c|c|c|c|c|}
\hline 모델명 & 제작사 & CCD & $\begin{array}{l}\text { FOV } \\
\text { (deg) }\end{array}$ & \begin{tabular}{|c|} 
정밀도 \\
피치,요/롤 \\
(arcsec)
\end{tabular} & $\begin{array}{l}\text { 크기 } \\
(\mathrm{cm})\end{array}$ & $\begin{array}{l}\text { 중량 } \\
(\mathrm{kg})\end{array}$ & $\begin{array}{c}\text { 소비전력 } \\
\text { (W) }\end{array}$ & $\begin{array}{c}\text { 온도조건 } \\
\left({ }^{\circ} \mathrm{C}\right)\end{array}$ & $\begin{array}{c}\text { 민감도 } \\
(\mathrm{Mv})\end{array}$ & $\begin{array}{c}\text { 처리속도 } \\
(\mathrm{Hz})\end{array}$ \\
\hline CT-601 & Ball Aerospace(미) & & $8 \times 8$ & $3(1 \sigma)$ & 178Dx295L & 8.2 & 12 & $-30 / 50$ & $+1 /+6$ & \\
\hline CT-602 & Ball Aerospace(미) & $512 \times 512$ & $7.8 \times 7.8$ & $3(1 \sigma)$ & 203Dx198L & 5.4 & 8 & $10 / 60$ & $+1 /+6$ & 10 \\
\hline CT-611 & Ball Aerospace(미) & $512 \times 512$ & $10 \times 10$ & $15(1 \sigma)$ & $216 \times 168 \times 286$ & 8.26 & 12.5 & $-30 / 50$ & $-1 /+3.9$ & \\
\hline CT-621 & Ball Aerospace(미) & $512 \times 512$ & $20 \times 20$ & 11 & $178 \mathrm{D} \times 216 \mathrm{~L}$ & 5.4 & 12 & $-30 / 50$ & $+1 /+3.9$ & \\
\hline CT-631 & Ball Aerospace(미) & $512 \times 512$ & $20 \times 20$ & 20 & 127Dx127L & 2.3 & 12 & $-20 / 50$ & $+0.1 /+4.5$ & \\
\hline CT-633 & Ball Aerospace(미) & $512 \times 512$ & $20 \times 20$ & $4 / 38(1 \sigma)$ & 134Dx142L & 2.7 & 8 & $-25 / 45$ & $-0.1 /+5$ & 5 \\
\hline SED 12 & Sodern(프) & $\begin{array}{c}\text { Thomsons } \\
\text { TH7816 } \\
23 \times 23 \mu \mathrm{m}\end{array}$ & $7.5 \times 10$ & 3 & 141Dx230L & 2.5 & 208 & $-20 / 50$ & $-1 /+8$ & \\
\hline SED 16 & Sodern(프) & $1024 \times 1024$ & $25 \times 25$ & $3 / 15(3 \sigma)$ & $170 \times 160 \times 290$ & 2.7 & 7.5 & $-30 / 60$ & & 10 \\
\hline SED 26 & Sodern(프) & $1024 \times 1024$ & $25 \times 25$ & $3 / 15(3 \sigma)$ & $170 \times 160 \times 290$ & 2.7 & 7.5 & $-30 / 60$ & & 10 \\
\hline SED 36 & Sodern(프) & $1024 \times 1024$ & & $1 / 6(3 \sigma)$ & & 2.8 & 8.4 & $-20 / 60$ & & 8 \\
\hline ASTRO 10 & JENOPTIK(독) & $668 \times 520$ & $16.7 \times 12.5$ & $2 / 15(1 \sigma)$ & 140Dx264L* & $1.3 *$ & 11 & $-40 / 50$ & $\sim+4$ & 8 \\
\hline ASTRO 15 & JENOPTIK(독) & $1024 \times 1024$ & $13.8 \times 13.8$ & $1 / 10(1 \sigma)$ & 192D×496L* & 4.4 & 10 & $-30 / 55$ & $\sim+6.5$ & 4 \\
\hline HD-1003 & BF Goodrich(미) & $512 \times 1024$ & $8 \times 8 / 20 \times 20$ & & $380 \times 157 \times 112$ & 3.3 & 11 & $-20 / 50$ & $\sim+6$ & \\
\hline AST-201 & Lockheed(미) & & $9 \times 9$ & & & 4.5 & 16 & & & \\
\hline ST5000 & UW-SAL(미) & $768 \times 474$ & $9.2 \times 6.7$ & 0.8 & & 2.3 & 8 & & 8.7 & 10 \\
\hline $\begin{array}{c}\text { Modular } \\
\text { Star Tracker }\end{array}$ & Alenia Diefesa(이) & $288 \times 384$ & $4 \times 3 / 10 \times 10$ & 6 & $137 \times 134 \times 227$ & 3.5 & 10.5 & & $\sim+9$ & \\
\hline STT-200A & NEC(일) & $510 \times 1000$ & $64 \times 64$ & $16(3 \sigma)$ & $240 \mathrm{D} \times 100 \mathrm{~L}$ & 3.5 & 16 & & $\sim+6$ & \\
\hline WFS & TNO-TPD(네) & $288 \times 384$ & $30 \times 40$ & $0.06 \mathrm{deg}$ & $180 \times 150 \times 90 *$ & $2.5 *$ & $4 *$ & $-30 / 6$ & $\sim+2.5$ & \\
\hline MEFIST & TNO-TPD(네) & & $15 \times 20$ & 15 & $100 \times 102 \times 115 *$ & $1.3 *$ & $1 *$ & $-20 / 40$ & $0.2 \sim 6$ & 10 \\
\hline $\mathrm{HE}-5 \mathrm{AS}$ & TERMA(네) & $1024 \times 1024$ & $22 \times 22$ & 1 & $120 \times 120 \times 33 *$ & 1 * & 6.8 & $-40 / 20$ & $\sim 6.2$ & 4 \\
\hline ASC & DTU(네) & & & $1(3 \sigma)$ & $50 \times 50 \times 50 *$ & 1 & 7.8 & & & 4 \\
\hline$\mu \mathrm{ASC}$ & DTU(네) & & & $1(3 \sigma)$ & $50 \times 50 \times 50 *$ & 0.43 & 1.9 & & $\sim 20$ & 20 \\
\hline Caltrac & $\begin{array}{c}\text { ELMG } \\
\text { CAL Corp. }\end{array}$ & & $36 \times 27$ & $\begin{array}{c}0.005 / 0.02 \\
\operatorname{deg}(3 \sigma)\end{array}$ & 225Dx330L & 3.4 & $11-14$ & $-20 / 50$ & $\sim+7$ & \\
\hline- & CorningOCA & $512 \times 512$ & $25 \times 25$ & & $118 \times 128 \times 157$ & 1.2 & 8.5 & $-30 / 50$ & $\sim+5$ & \\
\hline- & LEOS(ISRO,인도) & $1024 \times 1$ & $8 \times 6$ & 10 & $120 \times 120 \times 400$ & 5 & & $0 / 25$ & $\sim+5$ & \\
\hline
\end{tabular}

* Camera Optic Head만 고려 



그림 5. HD-1003과 AST-201

1990년대 중반이후에 들어와 우주비행체의 체 계와 임무가 갈수록 정확하면서도 소형 경량화을 추구하게 되는 추세가 되고, 마이크로프로세서의 처리속도와 대용량의 메모리가 출현하면서 앞에 서 언급한 1 세대의 별추적기에 비해 보다 지능적 이고 자율적이면서도 소형경량의 구조를 가지고 있는 별추적기의 출현이 불가피하게 되었으며 Ball Aerospace와 HDOS가 상대적으로 2세대 별 추적기 ${ }^{(7)}$ 의 개발을 게을리 하는 사이에 lost-in-space 모드에서의 자율적인 기능, 5 $\operatorname{arcsec}$ 이하의 자세정밀도, $10 \mathrm{~Hz}$ 이상의 Update Rate, $10 \mathrm{~W}$ 이하의 저소비전력, $1-2 \mathrm{~kg}$ 내외의 경량 등의 조건을 갖춘 신개념의 2세대 별추적기가 대 거 등장하게 되었다. Lockheed의 AST-201, EMS Technologies 의 CALTRAC, Technical University of Denmark의 ASC, TERMA Elektronik of Denmark의 HE-5AS, Sodern의 SED-16, SED-26, SED-36, Sira Elctro-Optics과 Astrium UK가 공 동개발한 AST20등이 있다. 표 2는 앞서 언급된 주요 별추적기들의 사양을 표로 정리한 것이 다. ${ }^{(8,9,10,11,12)}$

\subsubsection{APS형 별추적기 ${ }^{(8,13,14,15,16)}$}

90년대 후반에 들어서면서 NASA JPL을 중심 으로 $\mathrm{CCD}$ 소자를 대체할 수 있는 $\mathrm{CMOS} \mathrm{APS}$ 를 이용한 별추적기의 연구가 활발하게 진행되었다. NASA JPL의 Fossum 등이 APS를 별추적기에 적용가능하다는 분석을 내 놓은 이후 여러가지의 사전 연구를 거쳐 1998년에 JPL의 Eisenman등이 $\mathrm{APS}$ 를 채택한 다목적 별추적기의 시제품을 개발 하였는데 ${ }^{(8)}$, Programmable Intelligent Microtracker 라고 명명한 이 별추적기는 $256 \times 256$ 의 디지털 $\mathrm{APS}$ 와 32비트의 RISC 마이크로콘트롤러를 탑재 하였으며 $400 \mathrm{~g}$ 의 중량에 $400 \mathrm{~mW}$ 소모전력, 3 $\operatorname{arcsec}$ 의 정밀도를 가진 소형이면서도 자율기능 이 포함된 고성능의 별추적기이다. 한편 미국의 AFRL(Air Force Research Laboratory)에서는 $\mathrm{APS}$ 보다 민감도와 동적 성능이 뛰어난 $\mathrm{APPS}$ 를 이용하여 $0.2 \operatorname{arcsec}$ 수준의 자세정밀도와 $2 \mathrm{~W}$ 이하
의 전력소모, $0.2 \mathrm{~kg}$ 의 중량을 설계목표로 하여 Texas Instrument의 TMS320C6000시리즈 DSP칩 과 SRAM을 내장한 초소형 별추적기의 시제품을 개발하였다. ${ }^{(13)}$

2000년대에 들어서서 Ball Aerospace에서는 FSC-701를 개발하였으며, AstroAero사에서 CMOS 센서을 이용하여 소형위성급 별추적기를 상용화하 는 데 성공하였으며 Draper Lab과 NASA 등에서 $\mathrm{CMOS}$ 센서를 기반으로 한 별추적기의 시제품을 개 발한 바 있다.

미국의 Ball Aerospace사에서 개발된 FSC-701 은 Cypress HAS(High Accuracy Sensor)소자를 이용하여 설계되었으며 1 개의 카메라 전자장치로 2 개의 광학계를 제어할 수 있으며 내방사선 수준 이 $30 \mathrm{krad}$ 까지 되도록 설계하였다.

미국의 AeroAstro사에서 개발되어 공급중인 MST(Miniature Star Tracker)는 $1 \mathrm{M}$ 픽셀급의 $\mathrm{CMOS}$ 센서를 기반으로 한 소형위성용 별추적기 이다. DSP기반의 프로세서를 채택, 저가형 COTS 버전과 Radiation Harden 버전이 있으며 3축 자 세정보를 $70 \operatorname{arcsec}$ 수준의 정밀도로 제공할 수 있으며 600 개의 별카탈로그를 기반으로 하여 4등 성까지 관측할 수 있는 민감도를 보유하고 있다. 타 자세센서의 자세정보를 제공받지 않고도 독립 적으로 자세결정을 수행할 수 있는 소위 'lost-in-space'기능을 보유하고 있으며 CCD보다 상대적으로 빠른 동특성을 활용, $10 \mathrm{deg} / \mathrm{sec}$ 까지 의 각속도하에서도 자세정보를 무리없이 제공할 수 있는 기능을 보유하고 있다.

한편, 유럽의 경우 $\mathrm{ESA}$ 와 영국의 $\mathrm{RAL}$ 을 비롯 한 기관에서 $\mathrm{CMOS}$ 센서기반의 별추적기의 시제 품을 개발한 바 있으며 EADS Sodern, 독일의 Jena Optronik, 그리고 이탈리아의 Galieo Avionica (Finmeccanica Co.의 Subsidiary) 에서 는 상용화에 성공, 저궤도와 정지궤도용으로 공 급하고 있다.

EADS Sodern ${ }^{(11)}$ 에 개발한 HYDRA는 자이로 없는 위성자세제어를 지향한 $\mathrm{CMOS}$ APS기반의

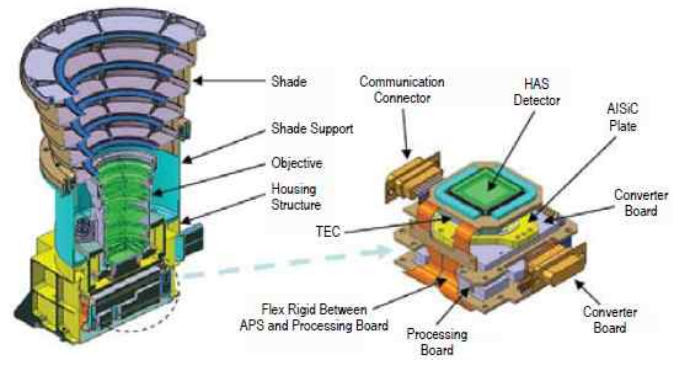

그림 6. Ball Serospace의 FSC-701 


\section{표 3. APS형 별추적기의 특성 비교}

\begin{tabular}{c|c|c|c|c} 
& FSC-701 & MST & HYDRA & ASTRO \\
\hline 제작사 & Ball & AeroAstro & Sodern & JENOPTIK \\
중량 & $1.6 \mathrm{~kg}(\mathrm{OH})$ & $0.3 \mathrm{~kg}$ & $2.2 \mathrm{~kg}$ & $1.2-1.8 \mathrm{~kg}$ \\
크기 $(\mathrm{cm})$ & $15 / 15 / 28$ & $5.4 / 5.4 / 7.6$ & $25 / 25 / 20$ & $12 / 12 / 23$ \\
정밀도 & $8.7 \operatorname{arcsec}$ & $70 \operatorname{arcsec}$ & $10 \operatorname{arcsec}$ & $2 \operatorname{arcsec}$ \\
소비전력 & & $2 \mathrm{~W}$ & $12 \mathrm{~W}$ & $6 \mathrm{~W}$ \\
처리속도 & $30 \mathrm{~Hz}$ & $1 \mathrm{~Hz}$ & $30 \mathrm{~Hz}$ & 10 \\
$\mathrm{CMOS}$ & $1 \mathrm{M}(18 \mu \mathrm{m})$ & $1 \mathrm{M}(7 \mu \mathrm{m})$ & & $1 \mathrm{M}(15 \mu \mathrm{m})$ \\
\hline
\end{tabular}

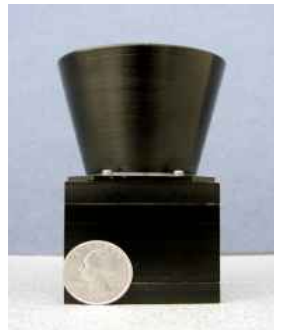

그림 7. AeroAstro의 MST


그림 8. HYDRA와 ASTRO APS

저중량, 저전력형의 별추적기이다. 자율기능이 강 화되어FDIR (Fault Detection, Isolation and Recovery) 기능이 구현되어 있으며, $30 \mathrm{~Hz}$ 의 갱 신속도를 가지고 $10 \operatorname{arcsec}$ 의 정밀도를 제공한다. Optical Head $(\mathrm{OH})$ 와 Electronic Unit(EU)으로 구 성되어 있으며 $\mathrm{OH}$ 를 구동하기 위해 $\mathrm{EU}$ 대신 탑 재컴퓨터를 이용할 수 있으며 여러개의 $\mathrm{OH}$ 를 동시에 장착하여 사용할 수 있도록 설계되어 있 는 장점이 있다.

독일의 Jena-Optronik(JENOPTIK) ${ }^{(12)}$ 에서 개발 한 $\mathrm{ASTRO} \mathrm{APS}$ 는 장기간 수명을 필요로 하는 통신, 과학, 관측용 저궤도 및 정지궤도 위성에 광범위하게 사용될 수 있도록 설계, 제작한 $1 \mathrm{M}$ 픽셀급 $\mathrm{CMOS} \mathrm{APS}$ 기반의 별추적기이다. 단일 헤드형이며 저중량, 저전력형 설계를 지향하고 있으며 수명이 18 년 이상 보장되며 정지궤도 환 경에서의 Radiation을 25년까지 견딜 수 있도록
설계되어 있다. 달이 시야각내에 들어올 경우에 도 $2 \operatorname{arcsec}$ 수준의 성능을 보장하며 20도의 시 야각을 제공하고 'lost-in-space'기능을 제공하는 차세대형 별추적기이다. ${ }^{(11,15)}$

\section{2 국내 개발동향}

우리나라에서 별추적기가 자체 개발되어 탑재 된 것은 한국과학기술원의 인공위성연구센터에서 개발하여 발사된 우리별 3호에서부터이다. 우리 별 3호의 별추적기는 30 도 $\times 23$ 도 의 상대적으로 넓은 $\mathrm{FOV}$ 와 $1 \mathrm{~kg}$ 의 중량과 $6 \mathrm{~W}$ 이하의 낮은 소모 전력을 갖도록 설계, 제작되었으나 정확도가 다 소 낮은 $1 \mathrm{arcmin}$ 급의 모델이며 2003년에 발사 된 과학위성 1 호에도 새로운 모델의 별추적기가 자체 제작되어 발사된 바 있으며 나로호에 의해 발사될 과학위성 2호에는 이중머리형 별추적기가 탑재되어 있다. 한편, 한국항공우주연구원과 TRW가 공동개발한 다목적실용위성 1 호에는 별 추적기가 탑재되어 있지 않으나 2006년에 발사된 다목적실용위성 2호 위성에는 Payload의 영상 해상도가 $4 \mathrm{~m}$ 에서 $1 \mathrm{~m}$ 로 조정되는 관계로 자세정 밀도 요구조건의 충족을 위해 Sodern사 ${ }^{(12)}$ 의 SED-16을, 2010년, 2011년에 각각 발사예정인 다 목적실용위성 5호, 3호에는 SED-26과 SED-36이 각각 탑재될 예정이다.

별추적기 기술은 국내에도 광학계 및 센서제 작 등의 하드웨어 기술과 별추적 알고리즘 및 자 세결정 소프트웨어 기술은 한국항공우주연구원, KAIST, 쎄트렉아이 등을 중심으로 상당부분 축 적되어 있음에도 불구하고 국내수요가 적고 국내 실용급위성에서의 신뢰도문제 등으로 인하여 국 산화를 시도하기 어려우며 기존 실용급 별추적기 시장의 대부분을 미국과 유럽이 양분하고 있는 상황은 별추적기를 우리나라 독자기술로 개발하 여 실용급 위성에 적용하는 걸림돌이라고 하겠 다. 교육과학기술부를 중심으로 추진중인 우주핵 심기술개발사업의 지원을 통하여 우리나라 고유 의 저가형 고성능 별추적기를 개발하고 검증위성 으로 계획중인 첨단소형위성에 시험탑재하여 충 분한 성능검증을 거친다면 5 10년내에 국내외 우주시장에 자국의 별추적기가 진출하여 경쟁할 수 있을 것으로 예상된다.

\section{IV. 결 론}

이상에서 별추적기 기술의 기본원리와 종류, 그리고 관련 기술 및 개발동향에 대해 알아보았 다. 세계적인 기술 추세를 보면 별추적기가 가장 
많이 활용되고 있는 인공위성의 경우 고신뢰도와 고정밀도를 지향하며 발전하고 있다. 별추적기는 지구센서나 태양센서 등의 타 자세센서에 비해 월등한 자세정밀도를 가지고 있어 고정밀 지향이 라는 시대적 요구를 가장 잘 만족하고 있으며 태 양센서나 지구센서가 자체정보만으로 인공위성의 3축자세를 결정할 수 없기 때문에 타 센서의 정 보를 탑재 소프트웨어를 통하여 종합처리를 해야 하는 반면 별추적기는 자체 소프트웨어의 처리를 통하여 3축 자세정보를 결정하므로 고신뢰도의 요구조건에도 잘 부응하는 센서이다. 별추적기의 가격이 대당 50 만불에서 200 만불에서 형성되는 것이 일반적이므로 우리나라에서 개발할 환경이 하루빨리 조성된다면 부가가치 면에서도 큰 이득 을 볼 수 있는 효과도 기대해 볼 수 있으리라 생 각된다.

\section{후 기}

본 연구는 한국항공우주연구원의 창의연구사 업인 “달 탐사선 개념설계 및 달탐사 핵심기술연 구”과제의 지원에 의해 수행되었습니다.

\section{참고문헌}

1) 최성봉 외, 인공위성 센서류 개발에 관한 연구, 산업자원부 연구기획사업 최종보고서, 한국 항공우주연구소, 1999 .

2) 이유 외, 위성용 Star Tracker의 설계 연구 (I), 산업자원부/과학기술부/정보통신부 위탁연구 보고서, 충남대학교, 1998 .

3) Wertz, J. R., Spacecraft Attitude Determination and Control, D. Reidel Publishing Company, Boston, MA, 1978.

4) Salomon, P. M. and Goss, W.C., "A Microprocessor-Controlled CCD Star Tracker", AIAA Paper 76-116, AIAA 14th Aerospace Science Meeting, Washington, D. C., January 1976.

5) Junkins, J. L., White, C. C., and Turner, J.
D., "Star Pattern Recognition for Real Time Attitude Determination", The Journal of the Astronautical Sciences, Vol. 25, July -September 1977, pp. 251-270.

6) Armstrong, R. W. and Staley, D. A., A Survey of Current Solid State Star Tracker Technology, The Journal of the Astronautical Sciences, Vol. 33, No. 4, 1985, pp. 341-352.

7) Eisenman, A. R., Liebe, C. C., and Joergensen, J. L., The New Generation of Autonomous Star Trackers, Sensors, Systems, and Next-Generation Satellites, Proceedings of SPIE, Vol. 3221, 1997, pp. 524-535.

8) Ju, G., Autonomous Star Sensing, Pattern Identification, and Attitude Determination for Spacecraft: An Analytical and Experimental Study, Ph.D. Dissertation, Texas A\&M University, College Station, TX, USA, May 2001.

9) http://www.ballaerospace.com/

10) http://www.goodrich.com/

11) http://www.sodern.com/

12) http://www.jena-optronik.com/

13) Liebe, C. C., Dennison, E. W., Hancock, B. R., Stirbl, R. C., and Pain, B., Active Pixel Sensor (APS) based Star Tracker, Proceedings of IEEE Aerospace Conference, Aspen, CO, March 1998, pp. 119-127.

14) Clark, N., Intelligent Star Tracker, Device and Process Technologies for MEMS and Microelectronics II, Proceedings of SPIE, Vol. 4592, 2001, pp. 216-226.

15) Schmidt, U., "ASTRO APS - The Next Generation Hi-Rel Star Tracker Based on Active Pixel Sensor Technology", AIAA 2005-5925, AIAA Guidance, Navigation, and Control Conference, August 2005.

16) 주광혁 외 3 인, "CMOS APS 센서의 인공 위성응용사례”, 항공우주산업기술동향, 5권 1호, 2007, pp. 56-64. 